\title{
Shaken, not Stirred: Comparing the Effectiveness of Pure and Hybrid Inflation Targeting
}

\author{
Philipp Kartaev, Lomonosov Moscow State University \\ kartaev@gmail.com \\ Irina Luneva, Lomonosov Moscow State University \\ irinaluneva97@gmail.com
}

\begin{abstract}
The study explores how the choice between pure and mixed (hybrid) inflation targeting affects the likelihood of achieving the announced inflation target achievement. Pure inflation targeting is deemed to be a regime under which inflation is the only variable in a central bank's objective function, while hybrid targeting is an alternative regime, which, in addition to inflation, includes the exchange rate in monetary authorities' objective function. Modeling is conducted on panel data of 32 inflation targeting countries. The cluster analysis method is applied to classify countries with respect to the regime used: pure or hybrid. Then a binary choice model of the probability of achieving the inflation target is estimated. The use of the hybrid option of inflation targeting is found to be associated with the increase in this probability, suggesting a higher effectiveness of this regime versus pure inflation targeting.
\end{abstract}

Keywords: exchange rate, passthrough effect, output, inflation targeting, panel data

JEL Codes: C23, E52, O42
Citation: Kartaev, P. and Luneva, I. (2018). Shaken, not Stirred: Comparing the Effectiveness of Pure and Hybrid Inflation Targeting. Russian Journal of Money and Finance, 77(3), pp. 65-75.

doi: $10.31477 /$ rjmf.201803.65

\section{Introduction}

The increasing popularity of inflation targeting has in recent decades given rise to a wide variety of approaches to the implementation of this regime by monetary authorities. While de jure most modern central banks look all but identical in terms of their main monetary policy goal of achieving price stability, de facto they are using a great variety of instruments to achieve it.

Seeking to enhance the efficiency of the standard monetary policy instrument (the interest rate), central banks have, in some cases, started to resort to substantial foreign currency interventions. It is not only in emerging but also in advanced economies, such as Japan, Switzerland, and Sweden, that monetary authorities 
have used this approach (Moiseev, 2017). Thus, in addition to pure inflation targeting, the hybrid option of this regime has gained wide acceptance.

In formal terms, pure inflation targeting is a monetary policy regime under which monetary authorities' objective function only includes the deviation of inflation from the target. In this case, a central bank does not undertake interventions in the foreign currency market (aside from extraordinary circumstances), achieving monetary policy goals primarily through the interest rate channel of monetary transmission, i.e., fully adhering to the free floating exchange rate regime. Hybrid inflation targeting, on the other hand, implies that the exchange rate is used as a monetary policy instrument (or is even part of the objective function, along with inflation). As part of this process, a central bank undertakes interventions and manages the exchange rate in order to reduce its volatility. It should be emphasized that what is meant is not the fixed exchange rate (because it is impossible to target inflation if the exchange rate is strictly fixed) but the managed floating regime, under which a central bank smooths out exchange rate movements caused by other than fundamental factors. One example of this policy's successful implementation is provided by the Czech Republic, which has, since 2015, combined inflation targeting with the stabilized exchange rate (the stabilized arrangement regime according to the IMF classification). ${ }^{1}$

The recent literature provides a number of arguments for managing the exchange rate under the inflation targeting regime. Aiurado et al. (2018), relying on the dynamic stochastic general equilibrium model, offer theoretical evidence of exchange rate management effectiveness for inflation targeting economies. The explanation that the authors suggest is that, under the free floating regime, minor inflation shocks may escalate into a significant and permanent inflation rise. If a central bank controls the exchange rate more strictly, this problem goes away. Mukhin (2017) suggests an open economy model with an endogenous currency choice for contract prices and shows that an optimal monetary policy should include measures to reduce exchange rate volatility. Trunin (2013) indicates a number of reasons why exchange rate control is worthwhile, at least for emerging economies: a rise in inflation and inflation expectations may stem from sharp exchange rate fluctuations. Since a large proportion of economic agents hold foreign currency assets, sharp exchange rate movements may provoke financial instability. In some cases, the exchange rate is the only instrument available in a less developed money market with an inefficient interest rate transmission mechanism. Shulgin (2018) shows that, under the inflation targeting regime, central banks can reduce exchange rate volatility by sterilized interventions in the form of foreign currency repo auctions. The viability of this strategy is confirmed using the vector error correction model

\footnotetext{
${ }^{1}$ Annual Report on Exchange Arrangements and Exchange Restrictions 2015. IMF, 2015. URL: http://www.imf.org/external/pubs/ft/ar/2015/eng/index.htm (as of 10.02.2017).
} 
on Russian daily 2014-2017 data. Shulgin arrives at a conclusion that sterilized interventions indeed help a central bank hedge the risk of temporary negative financial shocks without renouncing inflation targeting.

Pourroy (2012), using a sample of 16 emerging economies targeting inflation, finds that pure targeting is inferior to hybrid targeting, the latter being more efficient in bringing down inflation and its volatility. Pourroy's finding is based on data for years 2004-2009, i.e., the period when inflation targeting faced the greatest challenge in its entire history - that of the global financial crisis. And finally, Kartaev (2017) obtains empirical evidence that hybrid inflation targeting helps long-term economic growth more effectively than pure inflation targeting.

At the same time, discarding pure targeting in favor of the hybrid option, may entail negative consequences. Indeed, if a central bank targets inflation, attempting to manage the exchange rate at the same time inevitably reduces the credibility of its commitment to combating the high rate of price growth because then it becomes harder for the regulator to control inflation expectations. This may hamper the achievement of price stability, which is the main objective of inflation targeting.

Therefore, it makes sense to find out how the choice between pure and hybrid inflation target affects the probability of meeting the inflation target announced by a central bank. This is what this study aims to do.

To address this goal, we should first of all classify inflation targeting countries, assigning them to one of the two monetary policy regimes implemented. Our approach to handling this task is described in the next section of this paper. It provides arguments against the grouping of countries under the official (i.e. de jure) IMF classification. We use an alternative approach under which classification is based on monetary authorities' actual practices (like Levy-Yeyati and Sturzenegger, 2005) rather than on their declarations. Next, relying on the results of this classification, we construct a logit-model of target achievement probability depending on the option of inflation targeting regime and other relevant factors.

\section{Econometric modeling methodology and data}

The easiest way of grouping countries would be to use the available IMF classification of exchange rate regimes. Under this approach, economies which, according to the IMF data, rely on the fully floating exchange rate regime should be assigned to the group of countries using pure inflation targeting. This empirical strategy is, for instance, employed in Kartaev (2017). This approach, however, has an important disadvantage: as Levy-Yeyati and Sturzenegger (2005) show, the official exchange rate regime recorded in the IMF classification may be at odds with a central bank's actual practices. Specifically, many 
countries claiming to have the free floating exchange rate in fact manage this floating. This effect is termed "fear of floating" in the literature (see Calvo and Reinhart, 2002).

This study therefore uses the country classification based on the actually observed practices of monetary authorities. To implement this approach, relevant data on inflation targeting countries was collected and their exchange rate classification conducted using cluster analysis.

Free floating of the exchange rate involves minor foreign currency interventions coupled with unlimited exchange rate fluctuations. By contrast, the controlled exchange rate regime is defined as a situation where the exchange rate remains stable while interventions are volatile (Frankel, 1999). Classification should therefore be based on the two variables: the volatility of the national currency exchange rate and the volatility of central bank interventions in the foreign currency market.

Exchange rate volatility is defined as annual average variance of the national currency exchange rate to the dollar. Monthly data from January 2013 to December 2016 is used (to test the robustness of the results, data for the period beginning in 2000 is also used, see the section containing modeling results).

It is fairly difficult to measure central bank reserves, also, there is often an appreciable difference between change in reserves and interventions (Eichengreen et al., 1996). In order to reflect with maximum accuracy the part of reserves change which interventions account for, net reserves in terms of dollars are defined as follows (Levy-Yeyati and Sturzenegger, 2005):

$R_{t}=\frac{\text { ForeignAssets }_{t}-\text { ForeignLiabilities }_{t}-\text { CentralGovDeposits }_{t}}{e_{t}}$,

where (ForeignAssets - ForeignLiabilities $_{t}$ ) is the central bank's net foreign assets in terms of the national currency; CentralGovDeposits $s_{t}$ is national currency-denominated government deposits with the central bank; $e_{t}$ is the national currency exchange rate to the dollar. All the variables are the averages for the period concerned.

Monthly interventions in the foreign currency market are computed from the formula (Levy-Yeyati and Sturzenegger, 2005):

$$
r_{t}=\frac{R_{t}-R_{t-1}}{\frac{\text { MonetaryBase } e_{t-1}}{e_{t-1}}}
$$

where MonetaryBase M $_{t-1}$ is the monetary base for the preceding period. Reserves volatility is measured as average annual variance.

Among inflation targeting countries, there are energy exporters applying a particular version of the budget rule which determines the mechanism for saving and spending export revenues accumulated in stabilization funds as well 
as foreign currency purchasing and selling. Norway and Russia can be cited as appropriate examples. In this situation, a central bank may operate as the government's financial agent and change reserve assets in keeping with the budget rule. Although in this case change in reserves is not formally driven by the objective of exchange rate management or achievement of the inflation target, de facto, it helps reduce exchange rate volatility. Hence our classification regards such countries as economies with the hybrid regime.

Monthly data on exchange rates, government deposits, and net foreign assets are obtained from the International Financial Statistics (IFS) ${ }^{2}$ database. The sample includes 32 countries claiming to have the inflation targeting regime (see Appendix 1).

The classification is conducted using the cluster analysis method (the method of k-means). Before the countries have been broken down by cluster, both variables are $z$-normalized (in order to exclude a relationship between classification results and the magnitude of the measurement units).

Based on the classification under Levy-Yeyati and Sturzenegger (2005), all the observations are split into two classes:

1. Countries with high exchange rate volatility and low reserves volatility are classified as those adhering to the fully floating exchange rate regime.

2. Countries with low exchange rate volatility and high reserves volatility are deemed to have the managed exchange rate regime.

Since all the countries of the sample implement inflation targeting, all the observations assigned to the first class should be treated as the cases of pure inflation targeting, while countries assigned to the second class - as the cases of hybrid inflation targeting. ${ }^{3}$

To assess the comparative effectiveness (in terms of achieving inflation targets) of pure and hybrid inflation targeting, the following binary choice model is used:

$$
P\left(Y_{i t}=1 \mid z_{i, t}\right)=\frac{1}{1+e^{-z_{i, t}}},
$$

where $Y_{i t}$ is a dummy variable equal to one if $i$-th country met the inflation target in year $t$. For countries setting an inflation target band, meeting the target means that actual inflation has been within this band. For countries setting a more precise target (rather than a band), meeting the target means actual inflation deviation of no more than 0.5 percentage points (p.p.) from the target.

\footnotetext{
${ }^{2}$ International Financial Statistics. URL: http://data.imf.org/IFS (as of 03.03.2018).

3 The sample contains no countries simultaneously showing equally high volatility of both variables, which emphasizes a trade-off between the two policy types. The classification of countries with low volatility of both variables is a more subtle issue. A procedure proposed by Levy-Yeyati and Sturzenegger (2005) is employed for this group of countries: a separate subsample is made up of them, and a new classification is conducted. All the countries are classified as a result. To test the robustness of the results, a supplementary model estimation is performed, with all "debatable" countries assigned to the pure inflation targeting cluster, which has no effect on the findings.
} 


$$
z_{i, t}=\beta_{0}+\beta_{1} * \text { Hybrid }_{i, t-1}+\delta * X_{i, t-1}+\mu_{i}+\varepsilon_{i t},
$$

Here Hybrid ${ }_{i, t-1}$ is a dummy variable equal to one if a country manages the exchange rate (i.e., under the classification conducted at the first stage of modeling, is assigned to the class of countries with the hybrid inflation targeting regime).

$\mu_{i}$ is a fixed effect included to control for all country-specific characteristics slowly changing in time.

$X_{i, t}$ is a vector of the control variables. The control variables included in the model are the rate of inflation, the width of the inflation target band, changes in exchange rate, and real GDP growth rate. It is important to take account of the inflation rate because high inflation in preceding periods probably makes it harder to achieve price stability. The band width allows controlling for the fact that, by setting a wide inflation target band, a central bank makes it easier for itself to meet the inflation target in formal terms. Substantial exchange rate volatility may result in overall price level fluctuations due to the pass-through effect, thereby hampering the achievement of the inflation target. Finally, the high rates of output growth may suggest economy overheating, which makes it harder to maintain price stability. Instead of the GDP growth rate, the output gap (relative deviation of actual GDP from its potential level) could have been used, but we have to reject this approach because this would have reduced the sample drastically (data on the output gap is only available for some of the countries).

Changes in exchange rate rise are measured as the period-average growth rates of the exchange rate from the previous year. Inflation is computed as an annual change in the average consumer price index. GDP change is measured as GDP growth from the previous year at constant prices, in percentage terms. The width of the inflation target band is the difference between the upper and lower bounds of this band. All the regressors are included in the model with a one-period lag in order to reduce the risk of coefficient estimate bias due to the endogeneity problem.

Data on monetary policy regimes is obtained from the International Monetary Fund Annual Report 1990-2015, ${ }^{4}$ data on exchange rates - from the International Monetary Fund International Financial Statistics, ${ }^{5}$ all the other data - from the International Monetary Fund World Economic Outlook Database. $^{6}$

\footnotetext{
${ }^{4}$ International Monetary Fund Annual Report (1990-2015).

URL: http://www.imf.org/external/pubs/ft/ar/2015/eng/index.htm (as of 10.02.2017).

${ }^{5}$ International Monetary Fund International Financial Statistics. URL: http://data.imf.org/IFS (as of 03.03.2018).

${ }^{6}$ International Monetary Fund World Economic Outlook Database. URL: http://www.imf.org/external/pubs/ft/weo/2016/02/weodata/index.aspx (as of 03.03.2017).
} 


\section{Results of modeling the probability of meeting the inflation target}

The country classification with respect to the inflation targeting options obtained by cluster analysis is presented in Appendix 1. Individual countries for which data is available are assigned to one of the two classes for each year. Classification based on the IMF data is also presented in Appendix 1 for comparison.

Figure 1. Dynamics of the exchange rate and of foreign currency interventions in Norway

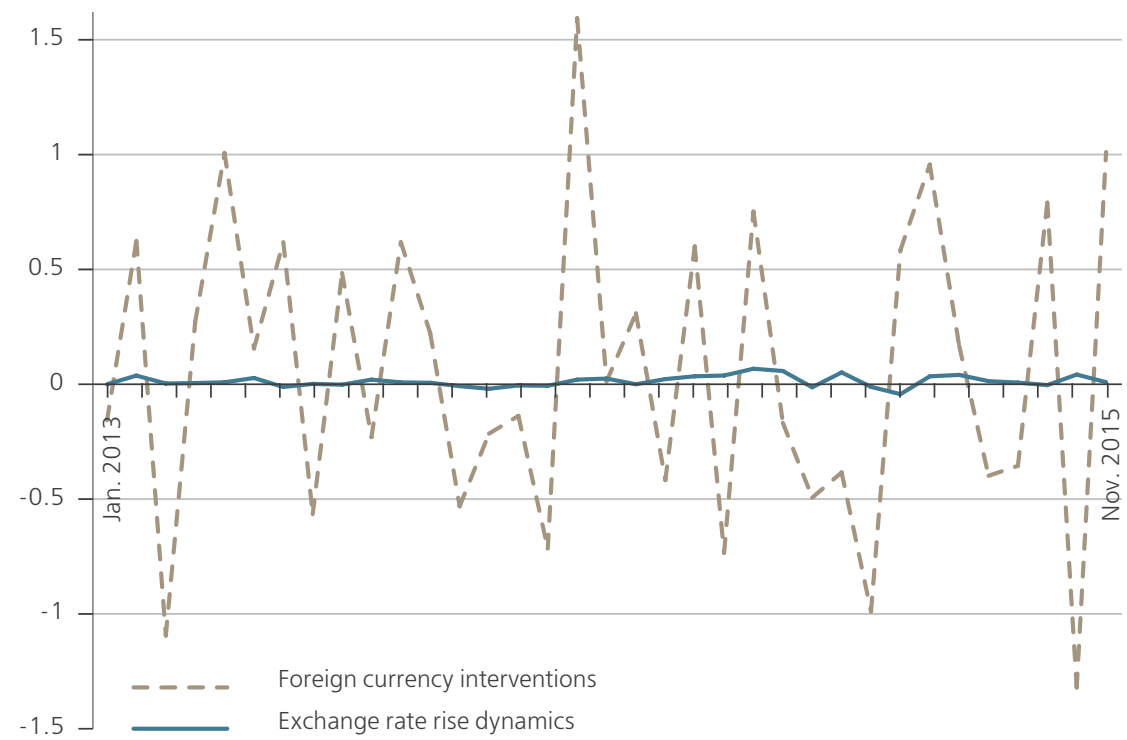

Note: The volume of interventions is computed from the formula for $\mathrm{r}_{\mathrm{t}}$, given in Section 2. Monthly data for years 2013-2015 is used.

To provide an example showing the advantages of our approach over the standard IMF classification, we will consider one of the countries from our sample. Figure 1 shows Norway's exchange rate movements and changes in foreign currency interventions in 2013-2015. It is easy to see that Norway's monetary authorities kept the exchange rate practically unchanged for several years through substantial changes in reserves. It would, of course, make sense to classify this kind of policy as the managed exchange rate regime, which is exactly what happens when our methodology, based on central banks' actual practices, is applied (see Appendix 1). The IMF classification, however, refers Norway to countries with the freely floating exchange rate in the period concerned, while this does not fully agree with the data observed, as shown in Figure 1. 
Table 1. Results of estimating the probability of achieving the inflation target in relation to the inflation targeting (IT) regime used

\begin{tabular}{|c|c|c|c|c|}
\hline Regressor & Model 1 & Model 2 & Model 3 & Model 4 \\
\hline Hybrid IT & $\begin{array}{l}1.299^{* *} \\
(0.6529)\end{array}$ & $\begin{array}{l}1.310^{* *} \\
(0.6420)\end{array}$ & $\begin{array}{c}1.298^{\star} \\
(0.6577)\end{array}$ & $\begin{array}{l}1.553^{* *} \\
(0.700)\end{array}$ \\
\hline Inflation & $\begin{array}{l}-0.1284^{*} \\
(0.0694)\end{array}$ & $\begin{array}{l}-0.1141^{*} \\
(0.0809)\end{array}$ & $\begin{array}{l}-0.1127 \\
(0.0823)\end{array}$ & $\begin{array}{l}-0.135 \\
(0.093)\end{array}$ \\
\hline Target band width & $\begin{array}{c}0.3505 \\
(0.3561)\end{array}$ & $\begin{array}{c}0.3551 \\
(0.3595)\end{array}$ & $\begin{array}{c}0.3569 \\
(0.3602)\end{array}$ & $\begin{array}{c}0.608 \\
(0.416)\end{array}$ \\
\hline Exchange rate changes & - & $\begin{array}{l}-1.033 \\
(2.406)\end{array}$ & $\begin{array}{l}-1.102 \\
(2.542)\end{array}$ & $\begin{array}{l}-0.615 \\
(2.657)\end{array}$ \\
\hline GDP growth rate & - & - & $\begin{array}{l}-0.01041 \\
(0.1028)\end{array}$ & $\begin{array}{l}-0.055 \\
(0.115)\end{array}$ \\
\hline $\begin{array}{l}\text { Volatility of national } \\
\text { currency exchange rate }\end{array}$ & - & - & - & $\begin{array}{l}-38.327^{\star} \\
(21.937)\end{array}$ \\
\hline $\begin{array}{l}\text { Volatility of central } \\
\text { bank interventions }\end{array}$ & - & - & - & $\begin{array}{c}0.032 \\
(0.169)\end{array}$ \\
\hline Constant & $\begin{array}{l}-1.841^{* *} \\
(0.8553)\end{array}$ & $\begin{array}{l}-1.806^{* *} \\
(0.8721)\end{array}$ & $\begin{array}{l}-1.776^{* *} \\
(0.9300)\end{array}$ & $\begin{array}{c}-8.748^{* *} \\
(4.276)\end{array}$ \\
\hline Adjusted pseudo- $\mathrm{R}^{2}$ & 0.05 & 0.05 & 0.05 & 0.06 \\
\hline $\begin{array}{l}\text { Likelihood function } \\
\text { logarithm }\end{array}$ & -45.53 & -45.45 & -45.45 & -42.44 \\
\hline $\begin{array}{l}\text { Marginal effect of } \\
\text { hybrid IT }\end{array}$ & $0.271^{\star *}$ & $0.273^{* *}$ & $0.270^{*}$ & $0.001^{\star *}$ \\
\hline $\begin{array}{l}\text { Marginal effect of } \\
10 \text {-unit exchange rate } \\
\text { volatility increase }\end{array}$ & - & - & - & $-0.155^{*}$ \\
\hline
\end{tabular}

Note: Numbers in the parentheses are robust standard errors. ${ }^{*}$ and ${ }^{* *}$ denote significance at the $10 / 5$ percent level respectively.

Results of estimating logit-models of the probability of meeting the inflation target with different sets of control variables are presented in Table 1 (see the Model 1 - Model 3 columns). It can be seen from the table that, regardless of the specification, the coefficient at the variable for hybrid inflation targeting is statistically significantly different from zero and has a positive sign. It can therefore be inferred that the hybrid monetary policy regime is associated with a higher probability of achieving the inflation target even with other factors controlled for. The marginal effect of switching to hybrid inflation targeting equals around 0.27 , meaning that adoption of this monetary policy regime increases the likelihood of meeting the inflation target by 27 p.p. The specific numerical value of the estimate should of course be treated with caution but the contribution of this variable to successful implementation of inflation targeting is likely to be fairly substantial.

To test the robustness of the results obtained, a number of the model's complementary specifications are analyzed. 
First, a model specification is estimated which, in addition to other control variables, included two variables used for country classification by monetary policy regime: exchange rate volatility and reserves volatility (see column Model 4 in Table 1). These variables are not included in the base specification because this carries a risk of multicollinearity with the Hybrid variable, which arises upon the construction of this variable. It is important to note that the variable for the hybrid targeting regime remains statistically significant even after these factors have been included. That said, its marginal effect declines, which is only natural because we now compute it with exchange rate volatility remaining unchanged, while what the main contribution of this regime consists in is exactly reducing the volatility of the national currency exchange rate. This is evidenced by an appreciable marginal effect of this variable, as shown in the last line of Table 1.

Second, the equation is estimated on the data for a longer period, beginning from 2000. As this period extension resulted in including substantially nonhomogenous periods in the sample (the 2008-2009 global financial crisis, for instance), a model including time-fixed effects taking account of this fact is estimated. The relevant results are presented in Appendix 2 (see columns Model 5 and Model 6). It can be seen from this Appendix that although the numerical estimates of the marginal effect of switching to hybrid inflation targeting decline somewhat (to about 20 p.p.) when estimation is conducted for a longer time span, the conclusion about the direction of this monetary policy regime's effect on the probability of achieving the inflation target remains generally robust to changing the estimation period. It is important to note that another factor that has a robustly significant effect on the likelihood of meeting the inflation target is inflation in preceding periods. This is a very natural conclusion: the higher was inflation in the preceding years, the more difficult it is to bring it down to the required level. The width of the target band remains non-significant. This is likely due to this variable's low variation in the sample.

And finally, third, the official IMF classification is used for computation as an alternative to the classification proposed in this paper (see column Model 7 in Appendix 2). The use of the IMF classification shows no positive effect of adopting the hybrid inflation targeting regime on the probability of achieving the target level of the nominal monetary policy anchor. This stems from the inadequacy of the official IMF classification, which is discussed above and emphasizes the importance of using the de facto regime classification proposed in this paper.

\section{Conclusion}

Econometric modeling conducted in this study does not provide any evidence that discarding pure inflation targeting in favor of hybrid targeting impedes the 
achievement of the inflation target. On the contrary, countries using the hybrid regime show a higher probability of achieving the required numerical value of the target.

This result may to a certain extent look paradoxical: central banks focusing solely on achieving the announced inflation level, handle this task less efficiently than those which, in addition to price movements in general, pay great attention to fluctuations in a different variable - that of the exchange rate. Nevertheless, this result is in line with theoretical considerations set forth in some of earlier research in inflation targeting (see, for instance, Mishkin and Schmidt-Hebbel, 2001) as well as more recent papers mentioned in the Introduction.

A possible explanation of this result is that the impact of exchange rate shocks on inflation expectations is asymmetric. In other words, if this shock is positive, inflation expectations rise appreciably, while a negative shock of the same magnitude in absolute terms produces a more modest decline in expectations. ${ }^{7}$ Consequently, a higher exchange rate volatility should trigger a rise in inflation expectations (even if the exchange rate itself remains unchanged on average), causing inflation to deviate from its target. Hence smoothing exchange rate fluctuations unrelated to changes in fundamental factors may be useful as part of hybrid inflation targeting. An argument for this conclusion is provided by a rise in the likelihood of meeting the inflation target owing to decreased volatility of the national currency, as suggested by the modeling results.

It would therefore be reasonable for emerging economies implementing the inflation targeting regime to explicitly set forth the goal of smoothing exchange rate fluctuations through the use of monetary policy instruments or alternative mechanisms, such as an appropriately organized budget rule. What is meant is not completely discarding the free floating of the exchange rate but purposefully reducing its volatility to a roughly equilibrium level.

A separate result of this study is that it provided country classification by inflation targeting regime: pure or hybrid, relying on the latest data and methodology proposed by Levy-Yeyati and Sturzenegger (2005). The classification results have a value of their own, as they can be used for further research examining comparative effectiveness of various monetary policy regimes.

Appendices are available at

www.cbr.ru/eng/money-and-finance;

dx.doi.org/10.31477/rjmf.201803.65

\footnotetext{
${ }^{7}$ See the Bank of Russia's Monetary Policy Guidelines for 2018-2020 (p. 9) URL: http://www.cbr.ru/eng/publ/ondkp/on_18-eng.pdf (as of 21.07.2018).
} 


\section{References}

Aiurado, M., Buffie, E. and Zanna, F. (2018). Inflation Targeting and Exchange Rate Management in Less Developed Countries. Journal of International Money and Finance, 81, pp.159-184.

Calvo, G. and Reinhart, C. (2002). Fear of Foating. The Quarterly Journal of Economics, 117(2), pp. 379-408.

Eichengreen, B., Rose, A. and Wyplosz, C. (1996). Speculative Attacks on Pegged Exchange Rates: An Empirical Exploration with Special Reference to the European Monetary System. NBER Working Paper, N 4898.

Frankel, J. (1999). No Single Currency Regime is Right for All Countries or at All Times. NBER Working Paper, N 7338.

Kartaev, F. (2017). Does Exchange Rate Management Improve Inflation Targeting Effectiveness? Dengi i kredit, 2017 (2), pp. 63-68 [In Russian].

Levy-Yeyati, E. and Sturzenegger, F. (2005). Classifying Exchange Rate Regimes: Deeds vs. Words. European Economic Review, 49(6), pp. 1603-1635.

Mishkin, F. S. and Schmidt-Hebbel, K. (2001). One Decade of Inflation Targeting in the World: What Do We Know and What Do We Need to Know? NBER Working Paper, N 8397.

Moiseev, S. (2017). Money with a Negative Interest Rate. Dengi i kredit, 10, pp. 16-26. [In Russian].

Mukhin, D. (2017). An Eqilibrium Model of the International Price System. Job Market Paper.

Pourroy, M. (2012) Does Exchange Rate Control Improve Inflation Targeting in Emerging Economies? Economics Letters, 116(3), pp. 448-450.

Shulgin, A. (2018). Sterilized Interventions in the Form of Foreign Currency Repos: VECM Analysis Using Russian Data. Russian Journal of Money and Finance, 77(2), pp. $68-80$.

Trunin, P. (2013). Inflation Targeting and Exchange Rate Policy under the Russian Economic Conditions. Rossiiskoye predprinimatelstvo, 14(19), pp. 69-74. [In Russian]. 